\title{
Rethinking Climate Change Governance and its Relationship to the World Tradiing System
}

\section{Scott BARRETT}

Scott BARRETt is the Lenfest-Earth Institute Professor of Natural Resource

Economics, Columbia University; sb3116@columbia.edu.

\section{Abstract}

International climate negotiations have thus far eschewed efforts to incorporate trade restrictions, but they have also failed to achieve their objective of reducing global emissions. Because of this failure, some countries are now inclined to act unilaterally and minilaterally, in many cases by imposing trade restrictions against third parties. Such actions are likely to invite retaliation. They could even ignite an escalating trade war. The best way to avoid such conflicts is not to limit the use of trade restrictions but to make international climate negotiations effective. Ironically, success in addressing climate change multilaterally may require incorporating trade restrictions in a new kind of climate agreement. ... . . .

Key words. Climate change, trade restrictions, international trade, international environmental agreements.

This paper was prepared for the conference on Climate Change Challenges and the World Trading System, held on 24 June 2011 at the Maison de I'Amérique latine in Paris. I am grateful to Jaime de Melo and my discussants, Mireille Chiroleu Assouline, Pascale Combes-Motel, and Daniel Gros for comments on an earlier draft. 


\title{
Rethinking Climate Change Governance
}

\section{and its Relationship to the World Trading System}

\author{
Scott Barrett ${ }^{*}$
}

Revised 14 July 2011

\begin{abstract}
International climate negotiations have thus far eschewed efforts to incorporate trade restrictions, but they have also failed to achieve their objective of reducing global emissions. Because of this failure, some countries are now inclined to act unilaterally and minilaterally, in many cases by imposing trade restrictions against third parties. Such actions are likely to invite retaliation. They could even ignite an escalating trade war. The best way to avoid such conflicts is not to limit the use of trade restrictions but to make international climate negotiations effective. Ironically, success in addressing climate change multilaterally may require incorporating trade restrictions in a new kind of climate agreement. Trade restrictions have been used successfully in other international agreements. But in these agreements, the primary purpose of the restrictions has been to encourage participation. That is, their primary purpose has been to enforce the agreement. This is the role trade restrictions ought to play in a new climate treaty. But for them to play this role, the design of climate treaties must change. If climate treaties are designed strategically, the threat to restrict trade will suffice to enforce the agreement; and if the threat to restrict trade is credible, and the

\footnotetext{
${ }^{*}$ SCOTT BARRETT is the Lenfest-Earth Institute Professor of Natural Resource Economics, Columbia University; sb3116@ columbia.edu. This paper was prepared for the conference on Climate Change Challenges and the World Trading System, held on 24 June 2011 at the Maison de L'Amérique Latine in Paris. I am grateful to Jaime de Melo and my discussants, Mireille Chiroleu Assouline, Pascale Combes-Motel, and Daniel Gros for comments on an earlier draft.
} 
punishment associated with the restriction severe, trade restrictions will not actually have to be used. By incorporating trade restrictions in this way, greenhouse gas emissions can be reduced without putting at risk the gains from multilateral cooperation in trade.

Key words. Climate change, trade restrictions, international trade, international environmental agreements. 


\title{
Rethinking Climate Change Governance
}

\section{and its Relationship to the World Trading System}

\author{
Running title: Rethinking Climate Change Governance
}

\section{INTRODUCTION}

International trade and efforts to lower greenhouse gas emissions, so as to limit global climate change, are inextricably linked. They have yet to be linked formally, but this situation is likely to change.

Change always entails risks. In this case, the risks are both to the trading system and to efforts to limit climate change. Formal linkage could harm either or both. It could also strengthen either or both. How all of this turns out will depend on the way these issues are linked.

Up to now, the two arrangements have been kept isolated from each other. The trade rules have not been modified to accommodate climate policy (though they have evolved over the years since climate negotiations began). Climate policy has not impinged on trade. But, so far, climate policy has been ineffective. Many people think it could be made more effective if linked to trade. This is where the pressure for change will come from - the climate side. ${ }^{1}$

The emerging climate regime has yet to take definite shape. A multilateral framework was launched in 1992 and continued to be developed through 2001. But ever since the United States announced that it would not participate in the Kyoto Protocol, the regime has faced an

\footnotetext{
1 See Whalley (2011), section 3, for a summary of the history of the mention of international trade in the climate negotiations.
} 
uncertain future. ${ }^{2}$ The Kyoto Protocol entered into force, and steps were taken by some countries to implement the agreement, but support has been uneven. A major problem for Kyoto is that the agreement's obligations terminate in 2012. Not knowing what was to come next, countries had little incentive to invest in the agreement. The climate talks held in Copenhagen were meant to establish the regime's future. But the formal negotiations failed. In Cancun a year later, the parties reaffirmed their support for the negotiation process, but this process has yet to develop an effective regime, and there is no consensus on how to move forward.

This vacuum will need to be filled. There is a strong chance it will be filled by countries acting unilaterally or minilaterally, and such a shift would pose a particular risk to the trading system.

Europe is already planning to impose a border measure. Beginning in 2012, airlines landing in or departing from European airports will need to obtain emission permits. ${ }^{3}$ In the first year, airlines will be allocated 97 per cent of historical emissions. Thereafter, the allocation will be held at 95 per cent. Initially 15 per cent of these permits will be auctioned, the rest given away. Failure to comply will be subject to enforcement, including the possibility that noncomplying airlines will be banned from operating within the European Union. Opposition to the measure has been strong. The United States has said that it will impose trade sanctions

\footnotetext{
${ }^{2}$ The failure of the United States to ratify Kyoto is obviously a problem. But the reasons the US failed to ratify Kyoto are perhaps more important. These were, first, the concern that the agreement would not address climate change, because it excluded the fast-growing developing countries from having to reduce their emissions-a problem exacerbated by leakage-and, second, the concern expressed by the Senate that it did not know what the US had to do to fulfill its commitments, and how much those actions would cost.
}

${ }^{3}$ Amendment to Council Directive 96/61/EC; see http://eurlex.europa.eu/LexUriServ/LexUriServ.do?uri=CONSLEG:2003L0087:20090625:EN:PDF. 
should the EU force US carriers to comply with the new directive (McCarthy 2010: 8). China has also threatened a trade war. ${ }^{4}$

Ideally, rules for international air travel would be agreed multilaterally through the International Civil Aviation Organization. However, the EU only acted because ICAO has so far failed to act. This illustrates the point I just made: if multilateral efforts to build an effective climate regime fail, the trading system will be at risk.

It's possible that the EU will pull back at the last minute, and limit the restriction to intra-EU travel. But avoiding a trade conflict in this way fails to do what needs to be done-reduce global emissions. If conflict is avoided this time around, the problem will only have been pushed down the road. So long as climate change is not being addressed, the trading system will be vulnerable.

There have been other proposals for incorporating trade restrictions. The bill passed by the United States House of Representatives (but not the Senate) in June 2009 (known as H.R. 2454) allows the president, from 2020, to require importers to obtain emission permits, unless an international agreement on reducing greenhouse gas emissions had been adopted in the meantime. The requirement would not apply to imports from countries meeting the same emissions criteria as the United States, but it is not clear how "comparability" would be established. The president can seek to waive this requirement, but his decision would need to be approved by both houses of Congress - a most unusual restraint on presidential authority.

Some European states have proposed a different remedy for the same problem. President Nicolas Sarkozy of France and Prime Minister Silvio Berlusconi of Italy have both said they would like the EU to impose a tariff to address carbon leakage. Other EU member states oppose such a policy, believing that it would likely trigger a trade war. But pressure for trade

\footnotetext{
${ }^{4}$ http://www.guardian.co.uk/environment/2011/jun/06/china-trade-war-emissions-trading-airlines.
} 
measures will only intensify if Europe continues to try to limit emissions at home, separate from a broader multilateral process.

The real challenge is to rethink the multilateral approach to addressing climate change. The approach tried so far has eschewed the use of trade restrictions, but it has also been ineffective. Ironically, this has made the trade system more vulnerable. Trade restrictions are incorporated in some of the most effective international environmental agreements. In some cases, the trade restrictions are explicit. In other cases they are so implicit as not to be noticed. In the cases in which they have been the most effective, they not only helped to address the environmental issue; they did so without injuring the trade system.

So far, proposals to use trade restrictions to support climate policy have been non-strategic. In every case, the restrictions are to be added on to a domestic policy, with little regard for how they would affect behavior. Put differently, their main purpose is to be used. This is in contrast to the successful deployment of trade restrictions in other international environmental agreements. In these cases, the purpose of the trade restrictions was to encourage participation in the agreement. This, as I shall explain, is how trade restrictions ought to be considered in a new climate treaty. But for them to play this role, the design of the multilateral approach will have to change.

The approach tried so far has failed mainly because it cannot be enforced. This creates a risk for the trading system as countries try to reduce emissions unilaterally, and then feel compelled to use trade restrictions. A better approach is to incorporate trade restrictions in multilateral agreements with their aim being to aid enforcement. Ironically, this will not only achieve more for the climate. It will also do more to safeguard the gains from multilateral cooperation in trade. 


\section{REASONS FOR ADOPTING TRADE RESTRICTIONS}

There are two primary motives for using trade restrictions, to limit leakage and to deter or punish free riding.

\section{a. Limiting Leakage}

What is leakage? Suppose there are $N$ countries, and that $n$ of these take actions to limit their emissions. The reduction in emissions by the $n$ countries is $x$ (measured in tons), but these actions cause emissions in the $N-n$ other countries to increase by $X$. The leakage rate is then $X / x$.

Leakage is transmitted through market prices. In particular, it is transmitted through international trade in both goods and services and fossil fuels. Climate change policy raises the cost of emitting greenhouse gas emissions at home, shifting comparative advantage in the greenhouse gas intensive industries towards countries that do not limit their emissions. As some countries reduce emissions, changes in comparative advantage will cause other countries to increase emissions. If the policy encourages substitution of zero- and low-carbon energy sources for high-carbon fuels, it will also lower the price of these fuels, causing other countries to increase their consumption of high-carbon fuels-thus, increasing their emissions. Leakage is a consequence of globalization.

The leakage rate will vary depending on the circumstances in which the climate policy is adopted. It will be lower the larger is $n$. It will be lower the smaller is $x$, since a greater reduction in emissions will tend to widen the gap in marginal abatement costs as between the countries that are and are not seeking to limit their emissions. If every country cooperates, by 
definition there can be no leakage. If no country reduces emissions, there can again be no leakage.

Normally, we would expect leakage to range from 0 to 100 per cent; a recent analysis estimates that full implementation of Kyoto would be associated with a leakage rate of around 20 per cent (Elliott et al., 2010). ${ }^{5}$ But it's possible leakage could exceed 100 per cent (Babiker, 2005), or be negative (Fullerton and Karkey, 2010).

Leakage will be higher for the energy-intensive, trade-sensitive sectors, which also tend to be concentrated. ${ }^{6}$ A review of the literature by the International Energy Agency (Reinaud, 2008) reveals some very large values. A tax of just $\$ 21 / \mathrm{tCO}_{2}$ applied in Japan and the EU-15 results in leakage of 55 per cent for iron and steel; a tax of $€ 20 / \mathrm{tCO}_{2}$ applied to the EU-27, would be associated with leakage of $0.5-25$ per cent for iron and steel and 40-70 per cent for cement. These tax values are close to the prices being realized by the Emissions Trading Scheme, and yet observed leakage has been small to non-existent. This may be due partly to allocations being given away free (Reinaud, 2008). But the main reason is probably that the Emissions Trading Scheme has so far had very little effect on emissions and so could not have much of

\footnotetext{
${ }^{5}$ This is for a tax of $\$ 29 / \mathrm{tCO}_{2}$; the current price of permits traded on the EU's Emissions Trading Scheme is about $\$ 23 / \mathrm{tCO}_{2}$.

${ }^{6}$ Market structure can have a huge effect on leakage. Imagine, for example, an industry in a contestable market. This is a market in which there are no sunk (exit) costs, and no entry costs. These markets are vulnerable to hit and run competition. If costs rise in one country, due to climate policy, firms will simply relocate to other countries-the leakage rate will be 100 per cent! While this may seem an extreme situation, it is a reasonable approximation of some markets-notably, the ability of fishing vessels to get around catch limits by reflagging.
} 
an effect on leakage. ${ }^{7}$ If Europe diverges more from the rest of the world, leakage is likely to increase.

A full border tax adjustment can partially neutralize leakage. Such an adjustment would tax imports to reflect the cost that would have been paid had production abroad been subject to the same climate policy as production at home. It would also rebate exports to reflect the same differential. The idea would be to neutralize the effect of the climate policy on marginal costs and, hence (indirectly), on prices. Note, however, that a border tax adjustment would have little effect on energy prices and so would not eliminate this source of leakage.

More importantly, it is impractical to calculate the emissions associated with the manufacture of a product. Inevitably, a crude rule would need to be applied, making the restriction less effective—and, very likely, more contentious.

\section{b. Deterring or Punishing Free Riding}

Trade restrictions may also be used to deter or punish free riding. Relative to a border tax adjustment, which aims to neutralize leakage, trade restrictions used to limit free riding would aim to limit the emissions of non-cooperating countries even more.

Joseph Stiglitz has proposed using trade restrictions as "an enforcement mechanism to prevent a country like the United States, or any country which refuses to agree or to implement emission reductions from inflicting harm on the rest of the world." In particular, he has recommended that other countries "prohibit the importation of American goods produced using energy intensive technologies, or, at the very least, impose a high tax on them, to offset the subsidy that those goods currently are receiving." In contrast to a border tax adjustment,

\footnotetext{
${ }^{7}$ Estimating the effect of the Emissions Trading Scheme on emissions is incredibly difficult, since "business as usual" emissions are not observable; see Ellerman and Buchner (2007).
} 
the aim of this proposal would be to "force states that inflict harm on others to behave in a better fashion." In short, the intent would be to enforce participation in a cooperative agreement (the United States is the only non-participating state of any consequence).

Notice two things about this purpose of a trade restriction. First, and in contrast to a border tax adjustment, the magnitude of the punishment is poorly defined. Second, if the restriction were to succeed in promoting participation it would in the bargain have succeeded in eliminating leakage.

\section{LESSONS FROM OTHER INTERNATIONAL AGREEMENTS}

Climate change is an unprecedented global challenge, but the world has had to address related problems in the past, and it has done so, sometimes successfully, using trade restrictions. What can we learn from this experience?

\section{a. North Pacific Fur Seal Treaty}

Negotiated in 1911, this is an ingenious treaty-its aim being to prevent exploitation of the fur seal at sea. Since international law allowed any country to exploit the fur seal in the high seas, a key task for the treaty was to deter entry by non-parties to the treaty. It did so by means of a trade restriction. In particular, the agreement banned imports of non-authenticated sealskins (the skins of seals killed by non-parties). Though there were only a handful of parties, the restriction worked because all seal skins were processed in London, and, as a Canadian delegate to the treaty negotiations observed, if the seal skins were "shut out of London, there would be no object in capturing them" (Barrett, 2003: 38). To my knowledge, trade was ever restricted. It was the credible threat to restrict trade that deterred entry by third parties. 


\section{b. International Convention for the Conservation of Atlantic Tunas}

The Fur Seal Treaty is the exception that proves the rule that the treaty is an imperfect instrument for fisheries conservation, given the customary law of freedom to fish on the high seas. A number of fisheries agreements have instituted trade bans, but their success has been partial. A trade ban can only be effective if fish can be authenticated (meaning, not illegal, unreported, or unregulated), and if excluded fish cannot be sold for profit in non-party states. The circumstances that made trade restrictions effective for the fur seal (London furriers having a unique hold on the market) were unique.

The International Convention for the Conservation of Atlantic Tunas (ICCAT) has been particularly active in imposing import bans against parties accused of illegal and unreported fishing, and against non-parties found to be fishing in a way that "diminishes the effectiveness of the ICCAT ...conservation measures." ${ }^{8}$ Sanctions were imposed on Panama, a non-party, in 1997, and a year later Panama acceded to the agreement (after which time the sanctions were lifted). The Recommendation lifting the trade ban welcomed Panama's accession to the agreement in late 1998, and acknowledged Panama's efforts to comply with the agreementincluding "not authorizing the registration of any bluefin tuna fishing vessel in the ICCAT area...." In other cases, however, the trade ban seems to have had little if any effect. Sanctions were imposed on Bolivia and Georgia eight or more years ago, and yet neither country has acceded to the agreement. The trade restrictions remain in force. ${ }^{10}$ There is irony

\footnotetext{
${ }^{8}$ The language here is standard, but is taken from the Recommendation for trade sanctions against Belize and Honduras; see http://www.iccat.int/Documents/Recs/compendiopdf-e/1996-11-e.pdf.

${ }^{9}$ http://www.iccat.int/Documents/Recs/compendiopdf-e/1999-09-e.pdf.

${ }^{10}$ Very recently, a proposal was put to the parties to the Convention on International Trade in Endangered Species (CITES) to ban international trade in bluefin tuna. If ICCAT were fully effective, this broader ban would be superfluous. The proposal required a two-thirds majority to carry but received much less than a majority of
} 
in this: when trade restrictions have the biggest effect (as in the Fur Seal Treaty), they have not needed to be imposed. When they have been imposed, they have had little if any effect.

\section{c. Montreal Protocol}

The Montreal Protocol, adopted in 1987, is one of the most successful efforts of international cooperation in history. A key reason for its success is a trade restriction-in particular, a ban on trade in controlled substances between parties and non-parties (the import ban took effect within one year of the treaty entering into force; the export ban took effect in 1993). It also bans imports of products containing controlled substances from and non-parties (exports to non-parties were not banned).

Interestingly, the Montreal Protocol does not ban imports produced with, but not containing, controlled substances from non-parties (such as electronics circuitry cleaned with CFC-113). The reason is partly that implementation of such a ban was believed to be infeasible (it was nearly impossible to tell whether a given product was produced using controlled substanceson computer circuitry, for example, CFCs do not leave a trace residue). As well, this trade ban was considered to be unnecessary. The ban on trade in controlled substances was sufficient to deter non-participation.

What were the reasons for incorporating these restrictions in the agreement? There seems to have been a mixture of motives (Barrett, 2010). However, arguably the most important motive was to enforce participation in the agreement (Benedick, 1998: 91), not least because, were

\footnotetext{
votes (Stokstad, 2010). Japan, the main importer of bluefin tuna, actively opposed the resolution, which was supported by another founding member of ICCAT, the United States. Interestingly, Webster (2011) suggests that an attempt to list bluefin tuna under CITES in 1991 had a temporary effect in improving ICCAT management.
} 
the restrictions to achieve this goal, they would in the bargain eliminate leakage. As with the Fur Seal Treaty, the Montreal Protocol's trade restrictions were never imposed (their use was threatened), and yet there is strong evidence suggesting that they had a transformative effect. Theory and anecdotal evidence both suggest that the trade restrictions were essential to deter non-participation.

The Kyoto Protocol controls emissions of greenhouse gases not controlled by the Montreal Protocol. The reason for excluding these gases was simple-they were already being controlled effectively by the Montreal Protocol.

Kyoto also excluded greenhouse gas emissions arising from aviation and bunker fuels. This is because Kyoto's approach, which limits the emissions of individual countries, is not easily extended to international air and marine transport. It isn't obvious how to allocate the responsibility for these emissions. For example, in the case of ocean shipping, should the state from which a ship departs be responsible? Should the state of final destination be responsible? How about the state in which the vessel is registered? Another difficulty is that these sectors are strongly prone to leakage.

A second reason for separating out these emissions is that the organizations responsible for these sectors, the International Civil Aviation Organization and the International Maritime Organization, have been successful in limiting other emissions. One reason for this, as I shall now explain, is that both agreements incorporate trade restrictions.

\section{d. MARPOL}

The International Convention for the Prevention of Marine Pollution from Ships, known as MARPOL, was adopted in 1978 and entered into force in 1983. Today, this agreement has 149 parties, making up over 99 per cent of world tonnage. The agreement does not incorporate trade restrictions directly. But it does establish technical standards for tankers, and 
obligates member states to prevent ships not complying with the standards from entering their ports.

The agreement is successful because marine transport is a network. A ship's value increases in the number of ports to which it has access. As more ports mandate the new standard, the returns to meeting the new standard go up. If only a few countries mandate the standard, it may not pay others to mandate it. But once enough countries adopt the standard, the incentive for the remaining countries to mandate the standard may become overwhelming.

This approach is particularly relevant to climate policy because countries first tried to limit the release of oil into the sea directly, with quantitative limits (just like the Kyoto Protocol). That approach failed. Technology standards were a second attempt, and they have succeeded spectacularly.

A common complaint about technology standards is "lock in"-the fear that technical standards, once established, will not change. The history of MARPOL suggests that this fear is overblown. The standards have evolved. Most recently they evolved to incorporate double hulls.

MARPOL has six annexes, the sixth being concerned with air pollution. Annex VI was adopted in 1997, and limits air pollution from ships. The NOx requirements establish performance standards for marine diesel engines, with compliance being demonstrated by the engine manufacturers. New limits for sulfur emissions have also been established. These are product standards, though the standards can also be met by installing on-board scrubbers. All of these standards are global.

MARPOL could be amended to address climate change. A recent analysis by McCollum et al. (2009) suggests that new fuel standards could lower emissions more than a third (relative to 
business as usual) by 2050 and that new technical standards for ship design and propulsion could reduce emissions by more than 15 per cent.

\section{e. International Civil Aviation Organization}

The International Civil Aviation Organization (ICAO) sets standards for international air travel in areas like safety and the operation of aircraft. It also establishes aircraft engine emission standards for pollutants such as nitrogen oxides and carbon monoxide. A state can adopt these standards in its national laws, preventing aircraft that violate the standards from landing within its territory. The commercial aircraft industry is highly concentrated, making international standards particularly easy to implement.

As with marine transport, the standards for air transport have evolved. ICAO first established emission standards in 1981. New standards reduced NOx emissions by a further 20 per cent in 1993. These were strengthened again in 1999 and 2005. Further restrictions have been proposed for implementation in 2013.

So far, neither the International Maritime Organization (IMO) nor ICAO has been effective in limiting the $\mathrm{CO}_{2}$ emissions of these sectors, which explains why the European Union is planning to incorporate international air transport emissions within its Emissions Trading Scheme. However, this situation may change (helped, perhaps, by the EU's threat to act unilaterally). In December 2009, ICAO announced a "Programme of Action" to develop "the first globally-harmonized agreement from a sector on a goal to address its $\mathrm{CO}_{2}$ emissions."11

11

http://unfccc.int/files/methods_and_science/emissions_from_intl_transport/application/pdf/sbsta_31_ic ao_statement.pdf 
The aim is to improve fuel efficiency 2 per cent, and to develop a global $\mathrm{CO}_{2}$ standard for aircraft. ICAO is also exploring standards for alternative fuels.

One reason the IMO and ICAO have not been more successful is that they set global standards. The Kyoto Protocol, by contrast, imposes obligations only on industrialized countries. Poorer countries, especially the large, fast-growing developing countries, have sought to maintain this distinction. However, this distinction is also a main reason why Kyoto has failed. It is one of the reasons the United States would not ratify Kyoto.

\section{WHY THE KYOTO PROTOCOL IS ILL SUITED TO USING TRADE RESTRICTIONS}

One important difference between the Montreal and Kyoto Protocols is that Kyoto limits the emissions produced by a country, whereas Montreal limits both production and consumption of controlled substances, with "consumption" being defined as production plus imports minus exports. The Montreal Protocol's basic obligations entail restrictions on trade. Kyoto's obligations do not.

This design feature also means that Kyoto gives a misleading impression of achievement. For example, between 1990 and 2008, emissions by the United Kingdom (defined as production) fell 14 per cent, whereas the emissions associated with UK consumption increased by almost 20 per cent. ${ }^{12}$ It is not obvious why one measure should count but not the other.

UK emissions (production) fell not so much because of climate policy but economic restructuring. The shift may or may not have been influenced by leakage, but certainly a policy of limiting production and not consumption does not help to limit leakage. Making matters worse, Kyoto does not limit the emissions of developing countries, including the fast-

\footnotetext{
${ }^{12}$ See http://www.defra.gov.uk/statistics/environment/green-economy/scptb01-ems/. For a general analysis of this perspective, see Davis and Caldeira (2010).
} 
growing, large economies like China, where many of the goods being imported by the UK are being produced (Davies and Calderia, 2010). Montreal limited the emissions of every country. Which countries would be targeted by trade restrictions? The obvious target would be the United States, since it is the only non-participating country. But if this were the criterion, then the US could accede to the treaty to avoid trade restrictions. Of course, it would then risk being in non-compliance, since Kyoto requires that the US cut its emissions 7 per cent from the 1990 level through 2008-2012, and US emissions increased 13 per cent through 2008. But if non-complying countries were to be targeted, the list would have to include more countries. Canada is obligated to cut its emissions 6 per cent, and yet its emissions have grown 24 per cent. Other countries likely not to comply with Kyoto include Australia, Iceland, New Zealand, and Norway. The European Union is on course to meet its Kyoto target, but many countries within the EU are well off their individual targets as determined by the EU burden sharing agreement. For example, Spain's emissions were 42 per cent higher in 2008 than in 1990, when the EU burden sharing agreement requires that Spain's emissions be no more than 15 per cent higher. Spain and other EU member states are not at risk of non-compliance only because the EU (uniquely) is treated by Kyoto as a "bubble." So long as the EU meets its aggregate emissions target, the emissions of individual countries are ignored for compliance purposes. Japan is exploiting a different loophole. It is seeking to comply by purchasing permits from other countries such as Ukraine, to which Kyoto allocated "hot air." That is, these transition countries are allowed to emit much more than their business as usual emissions. Ukraine can sell permits to Japan, to help Japan comply, but without reducing its own emissions.

Of course, making this even more complicated, the compliance period doesn't even end until 2012. And there seems little prospect of Kyoto being succeeded by a similar agreement. Canada, Japan, and Russia said at the recent G8 meeting that they would not participate in a 
follow on agreement. ${ }^{13}$ It is implausible that the US would be targeted for not participating when the agreement is literally falling apart.

Another difference between Montreal and Kyoto is that Montreal was enforced by the credible threat to restrict trade between parties and non-parties, and Kyoto lacks an enforcement mechanism.

Climate negotiators actually agreed to adopt a compliance mechanism in 2001. But according to Article 18 of the Kyoto Protocol, any compliance mechanism "entailing binding consequences" must be approved by amendment. An amendment is akin to a new agreement. It would only be binding on the parties that ratified it, provided at least three-quarters of the parties to the Kyoto Protocol also ratified it. Since no such amendment has been adopted, the mechanism agreed in 2001 is non-binding.

Even if the mechanism were binding, it would have no effect. The main component of the mechanism is a 30 per cent penalty. A country that emits, say, 100 tons more than the treaty allows in the first "commitment period" (2008-2012) must make up for this by reducing its emissions by an additional 130 tons in the next period. This reduction is "additional" relative to this country's next-period cap. This cap, however, is subject to the approval of the country having to pay the penalty. That country can therefore insist on a generous cap as a condition for joining, and so get away with paying a "phantom" penalty. Alternatively, it could ratify the new treaty and then fail to comply again - the current arrangement essentially carries forward the penalty indefinitely. The reason this penalty system cannot deter non-compliance is that its punishments must be self-inflicted.

\footnotetext{
${ }^{13}$ http://www.guardian.co.uk/environment/2011/jun/01/world-bank-failing-carbonmarkets?INTCMP=SRCH.
} 
This compliance mechanism also permits other parties to suspend the emissions trading privileges of a country found to be in non-compliance. But is the threat to withdraw this privilege credible? Would other countries impose this punishment? There is good reason to believe they would not, at least in some important cases (Kallbekken and Hovi, 2007). If a large seller of permits were in non-compliance, withdrawal of its trading privileges would push up international permit prices, harming net importers; the latter countries may therefore be unwilling to impose the punishment. If a large buyer of permits were punished in this same way, international permit prices would fall, harming net exporters; these countries may therefore also be unwilling to impose the punishment. Of course, in each of the cases I just mentioned, some countries would gain by imposing the punishments (net exporters in the first instance, net importers in the second). But with some countries gaining and some losing, activation of the sanction could spark conflict among the countries that had complied.

These ineffective mechanisms are to be contrasted with the procedures for enforcement adopted by other international agreements. For example, the multilateral trade agreements are enforced by tariffs that "rebalance" any violation. Countries are not expected to punish themselves for violating the trading rules. This is to be done by the countries harmed by the breach. Moreover, under this arrangement, punishments targeted at violators do not harm third parties. $^{14}$

\section{A POSSIBLE NEW CLIMATE REGIME}

\footnotetext{
14 The essential difference between enforcing a trade agreement and a climate agreement is that trade is a bilateral activity whereas climate change mitigation is a global public good. Bilateral agreements are easy to enforce; multilateral agreements seeking to supply a global public good are much harder to enforce.
} 
How might climate change be addressed in the future? There are numerous proposals, ranging from modifications of Kyoto (a single agreement, encompassing every aspect of mitigation) to bottom up approaches in which countries pretty much act independently. ${ }^{15}$ Both extremes are likely to fail. The former approach has not worked, and none of the proposals I am aware of show how it could be enforced. The latter approach ignores the need for collective action. My own proposal is to break up this big problem into smaller agreements, using the best means available for enforcing each one. This is a very imperfect proposal, but I believe it is better than the alternatives. The contrast essentially boils down to a trade off between environmental and cost-effectiveness. Kyoto is designed to be cost-effective, but is weakly enforced. A sectoral approach would have an enforcement advantage, but it would not be as cost-effective. Remarkably, this alternative approach has already been shown to work. The Montreal Protocol has already reduced the emissions of some greenhouse gases, and it did so using trade restrictions. I explain how and why this happened next.

\section{a. The Montreal Protocol as a Climate Treaty}

Ozone in the stratosphere is a greenhouse gas (protecting the ozone layer will thus add to climate change), as are the chemicals that deplete stratospheric ozone (reducing these emissions will thus help mitigate climate change) and many of their substitutes (use of these will thus add to climate change). What is the net effect of the Montreal Protocol on the climate? Calculations by Velders et al. (2007) conclude that the Montreal Protocol reduced greenhouse gas emissions four times as much as the Kyoto Protocol intended (and Kyoto, as explained earlier, will achieve much less than intended).

\footnotetext{
15 See, in particular, the proposals in Aldy and Stavins $(2007,2010)$
} 
In late 2007, the parties to the Montreal Protocol negotiated a new adjustment, agreeing to accelerate and expand the phase out of HCFCs, an ozone-depleting substance that happens also to be a greenhouse gas (HCFCs are controlled under the London amendment to the Montreal Protocol, not the Kyoto Protocol). Manufacture of these compounds produces hydrofluorocarbons (HFCs) as a by-product. HFCs do not deplete the ozone layer, and so are not regulated by the Montreal Protocol, but they are a very potent greenhouse gas — one of the six gases controlled by the Kyoto Protocol. Kyoto has done very little to limit HFCs. Montreal, by contrast, will do more, helped by the trade restriction between parties and nonparties.

\section{b. HFCs}

What Montreal has not done is to limit HFCs directly. This is because HFCs are not an ozonedestroying substance. But this situation may be about to change.

In May 2011, the United States, Canada, and Mexico proposed amending the Montreal Protocol to control HFCs. ${ }^{16}$ If adopted, such an amendment would represent a significant departure from the approach taken so far to address climate change. It would mean addressing one piece of the problem, rather than all of it in a comprehensive way. And it would likely involve using trade restrictions for purposes of enforcement. ${ }^{17}$

\footnotetext{
${ }^{16} \mathrm{~A}$ similar proposal was submitted by the Federated States of Micronesia; see http://climatel.iisd.org/news/us-canada-and-mexico-and-federated-states-of-micronesia-propose-hfcs-phase-downunder-montreal-protocol/.

17 This is not certain. For example, HCFCs were initially controlled by the Copenhagen Amendment to the Montreal Protocol (1992), but trade in HCFCs was restricted for the first time by the Beijing Amendment (1999). See Barrett (2010).
} 
Ironically, some countries have opposed addressing HFCs in the Montreal Protocol, because the design of this agreement would impose obligations on all countries (this is the same complaint noted earlier with respect to reducing emissions through ICAO and the IMO). The minutes to the 2010 Meeting of the Parties to the Montreal Protocol record one representative as saying, "that the inclusion of HFCs in the Montreal Protocol would imply the imposition of binding obligations on all parties to the ozone regime despite the fact that under the climate change regime such obligations applied only to Annex I parties to the Framework Convention on Climate Change...." ${ }^{18}$ But of course this is one reason why the Montreal Protocol has been successful, and why the climate regime has failed.

Importantly, and as noted by other delegates at this meeting, Montreal addresses "common but differentiated responsibilities" by giving developing countries more time to phase down their production and consumption of ozone depleting substances. It also gives developing countries financial assistance through the Multilateral Fund. By agreement, rich countries pay the "incremental costs" of compliance by poor countries.

Under Kyoto, poor countries are not subject to any emission limits, but rich countries can pay poor countries for emission reductions achieved under the Clean Development Mechanism. This is a different approach to involving developing countries in the global abatement effort, but it suffers from two problems. The first is that, with the CDM, since there is no hard cap on emissions, credits for emission reductions must be inferred, and so involves transactions costs. The second problem is that payments can exceed incremental costs. Indeed, it is possible that some states may be objecting to the proposal to control HFCs under Montreal for fear of losing the windfalls they are currently getting for reducing HFCs under the Clean

\footnotetext{
${ }^{18}$ See http://www.unep.ch/ozone/Meeting Documents/mop/22mop/MOP-22-9E.pdf, paragraph 57.
} 
Development Mechanism. ${ }^{19}$ Side payments are needed to address equity concerns. But if some countries are being over compensated, others must be over paying, and the latter will have an incentive to scale back their emission reduction ambitions as compared to an arrangement for financing based on incremental costs. If the CDM were closed down or reformed, there may be more interest in amending Montreal.

\section{c. Aviation Emissions}

Could standards reduce emissions in the aviation sector? Fuel standards already exist. They are needed because international air transport is a network. As explained by Rumizen et al.,

Industry fuel specifications....are used by the aviation fuel industry stakeholders to standardize and control the properties and quality of aviation fuel as it travels through the distribution system. The producers must formulate the fuel to meet the specification properties, fuel handlers in the distribution system such as pipeline companies must certify that the fuel meets the specification when delivering the fuel, aircraft engine designers must design their engines to operate over the range of fuel properties in the specification, and aircraft operators such as airlines must ensure that the fuel loaded on to their airplanes meets the criteria of the specification [Rumizen et al., 2010: 179].

What we need is a new standard. One approach would be to develop a fuel (such as biofuel blends) that can be used by the existing fleet of planes. Alternatively, a new fuel (such as hydrogen) could be developed, necessitating changes in the fleet. The first approach might be tried in the short run, the second in the long run. Standard setting is a process.

\footnotetext{
${ }^{19}$ Wara $(2006,2007)$ has described how, under the CDM, HFC emissions were reduced at a price far in excess of the actual cost.
} 
ICAO is also exploring development of a $\mathrm{CO}_{2}$ emissions standard for aircraft. The fuel efficiency of aircraft has improved over time (today's aircraft are 15 per cent more fuel efficient than comparable aircraft of a decade ago; see ICAO, 2010: 68), and is expected to continue to improve. A more radical approach would be to develop a breakthrough design (Blanco and Greitzer, 2010). If a new design were required by agreement, the standard would spread this technology worldwide-helped by trade restrictions, but without straining the trade system.

The difficulty with this approach is that improvements in technology are unlikely to keep pace with increasing demand for air travel. A different approach would be to lower demand, by increasing price. Yet another approach would be to reduce emissions by other means, such as by using "air capture" technologies to remove $\mathrm{CO}_{2}$ directly from the air.

\section{d. Iron and Steel}

Standards can be extended to other industries. Emissions of the trade-sensitive, energyintensive industries must be addressed globally, since leakage is likely to loom large for these sectors. The most important of these sectors are aluminium, glass, cement, and iron and steel making. To illustrate this point, I shall focus on this last sector.

There are two main processes for making iron and steel, the basic oxygen furnace and the electric furnace. The former is very emissions-intensive, mainly because of the need to transform iron ore into pig iron. The latter is less so, but requires scrap metal as an input. A number of breakthrough technologies are being investigated. One of these is the so-called Hlsarna steelmaking process. This has an advantage over the basic oxygen furnace process in that it can skip the need to create pig iron. A pilot Hlsarna project is now being built with the 
aim of reducing emissions 50 per cent relative to the basic oxygen furnace process. ${ }^{20}$ Suppose that the process can be demonstrated to work effectively. Then, an agreement could require that this process replace the basic oxygen furnace. Special financing would pay for the agreed "incremental costs" of switching to this new technology, coupled with the use of trade restrictions against countries that refuse to adopt the new standard. In this case, the trade restrictions could be in the form of a ban on steel imports. The idea would be that, by international agreement, a new level playing field would be created for iron and steel production. Equity issues would be handled by the compensating payments. The trade restriction would constitute the stick.

This raises the question of how we discover new ways of reducing emissions like the Hlsarna process. This came about due to the European Union's Ultra Low $\mathrm{CO}_{2}$ Steelmaking (ULCOS) initiative, which involves substantial funding by EU members in partnership with nearly 50 European companies. ${ }^{21}$ R\&D into new technologies is a complementary activity to standard setting. It requires public funding (because the knowledge acquired is a global public good), but it does not require global agreement ${ }^{22}$. A related example is funding for the ITER project for nuclear fusion research.

\section{e. Automobile Emissions}

Transportation is a key sector. One way to reduce emissions from this sector dramatically is to switch from the current global standard, comprising the internal combustion engine, powered by gasoline, to the electric car, powered by batteries. Such a switch will be helped by two

\footnotetext{
${ }^{20}$ See ULCOS Research at www.ulcos.org/en/research/home.php.

${ }^{21}$ See www.ulcos.org.

${ }^{22}$ As explained in Barrett (2007), this is a "single best effort" global public good, very different from the "aggregate effort" global public good of reductions in greenhouse gas emissions.
} 
phenomena, economies of scale (and learning) in manufacture and the network infrastructure for recharging and/or battery replacement. Of course, today, both of these phenomena are working to give the internal combustion engine a tremendous advantage. To spread, the electric car would need to overcome this historical advantage.

This will be difficult. Price incentives may help, but they may not be enough. For example, the switch away from leaded petrol in Europe was facilitated by tax policy that favoured unleaded petrol. But the switch was also helped by the new formulation being compatible with the old engine designs. The installed base of infrastructure and the inherited stock of cars did not impede the transition.

Fortunately, the switch to the electric car can be achieved in stages. Penetration of the plug-in hybrid vehicle is possible because these cars can also run on gasoline. Moreover, as the market share of plug-in hybrids increase, the infrastructure for recharging will grow. Similarly, there will be incentives to invest in R\&D to improve battery technology.

Ultimately, however, stronger policies may be needed. One possibility is for regulation to require that new cars be electric-meaning that new sales of internal combustion engines would be banned. This seems a radical suggestion, but it is similar to the approach taken recently to switch from analogue to digital television. The conversion was helped partly by the advantages of digital television (many people switched even when analogue was still available), partly by government subsidies for switching, and partly by the policy of turning off analogue signals. The public benefit justifying this radical policy was the freeing up of spectrum for other purposes. In the case of the electric car, the public benefits include reduced greenhouse gas emissions, reductions in other emissions (local pollution), and reductions in oil imports.

The car industry's strong preference for standardization is reflected in agreements like the Agreement Concerning the Establishing of Global Technical Regulations for Wheeled 
Vehicles. In this agreement, a global standard is adopted by consensus-no contracting party must vote against. ${ }^{23}$ In standards agreements, unlike emission reduction agreements, enforcement is easy (Barrett, 2007). Forming a common standard will be essential to the spread of this technology. Already efforts have been underway to establish recharging standards using 220 volt charging (which can be done at home) and rapid chargers (requiring special infrastructure). An effort is also underway to standardize systems for replacement batteries.

\section{f. Electricity generation}

Of course, if a switch to electric cars is to reduce emissions, electricity generation must also change. Electricity generation is a major source of emissions in any event.

In contrast to transportation, electricity generation is not networked. ${ }^{24}$ Electricity itself is networked, but the generation of power is not. Standardization in power generation can emerge, due to economies of scale and learning. For example, Cowan (1990) shows how these considerations favored the light water reactor for nuclear power. However, these forces alone are not so powerful that all power is generated by the same kind of electricity generation plant.

Controlling emissions from electricity generation is more like controlling emissions in the iron and steel sector. However, unlike iron and steel, electricity is not traded internationally very much. It may be possible to find trade leverage in some areas. For example, emissions

\footnotetext{
${ }^{23}$ This is a somewhat unusual requirement for a standards agreement. Normally, if enough countries agree to a standard, the others will pretty much have to fall in line. The reason is that there can be fragmentation if the markets are big enough and the costs of meeting different standards small enough. This explains, for example, why there can be both left and right hand drive cars.
} 
from aluminum manufacture are mainly due to the electricity input. A substantial portion of this power is hydroelectric. But about half is produced from fossil fuels. A new standard could be developed for the electricity input to aluminum production-perhaps a low or zero carbon standard. This could be enforced using a combination of carrots (financial assistance) and sticks (trade restrictions). However, as a general matter, it is hard to see how trade restrictions could be used to enforce an agreement limiting the emissions in the power sector only. Instead, we will have to rely on simpler measures, such as domestic enforcement and international benchmarking. This is essentially how the acid rain protocols have been enforced, but it is important to note that these enforcement mechanisms are weak (Barrett, 2003).

It is clear that carbon capture and storage is an important technology. And yet the incentives to undertake R\&D into carbon capture and storage are weak. These incentives derive from the prospects of this technology being diffused and used to reduce emissions worldwide (Barrett, 2006).

However, a standard for using this technology does have some attractions. Negotiations on emission reductions from a baseline are very difficult because of "the comparability problem." A common base year will favour some countries over others. For example, Kyoto's 1990 base year favours countries like Germany and Russia over countries like the United States and Japan. As well, because business as usual emissions are unobservable, it is also difficult to know whether any given emission reduction goal (relative to the baseline) entails "equal sacrifices."

Technology standards do not share this same problem. Consider, for example, a proposal to require that all new coal-fired power stations use carbon capture and storage by 2020 , and that all coal-fired power stations use carbon capture and storage by 2050 . In this case, 
history and business as usual are of little consequence. Standards are easier to negotiate than emission limits.

\section{COORDINATION}

As noted before, this fragmented approach has a disadvantage compared to Kyoto. It is not cost-effective. With different gases and sectors being addressed by different agreements, marginal costs will vary.

The difference should not be exaggerated. Kyoto is not cost-effective. Though Kyoto limits economy-wide emissions for some countries, these countries have chosen to implement Kyoto using a sector-based approach. For example, the Emissions Trading Scheme covers less than half of EU emissions. Also, Kyoto does not limit the emissions of developing countries, whereas the proposal I have sketched here emphasizes the need for global agreements for individual gases (like HFCs) and sectors. Most importantly, Kyoto has barely reduced global emissions. There is little value in a cost-effective approach if it fails to limit climate change.

There are different ways to ensure cost-effectiveness. One is by formal linkage. This is the market approach. Trading will tend to equalize marginal costs.

Linkage can also be informal. So long as marginal costs are observable, there will be a tendency for countries to ensure that they do not differ greatly. As with adjustments and amendments to the Montreal Protocol, it is likely that new agreements will need to pass a cost-benefit test, to prove their worth. A more comprehensive approach is also needed, to ensure that the overall objective is being met at reasonable cost. In short, there will need to be coordination among the various agreements. This role can be fulfilled by the Framework 
Convention, supported by technical expertise analogous to the Technology and Economic Assessment Panel of the Montreal Protocol. The climate negotiations have been intensely political. The Montreal negotiations were more technical. They were also more successful.

\section{CONCLUSIONS}

Trade restrictions were not incorporated in the design of the Kyoto Protocol, but that agreement has failed to reduce greenhouse gas emissions. Because of this, some countries are seeking to address climate change unilaterally or minilaterally, supported by trade restrictions. This approach is unlikely to succeed any better in reducing global emissions, but it will threaten the trade system. The best way to safeguard the trade system is to develop an effective multilateral regime for climate change. Ironically, to protect the trade system, trade restrictions need to be incorporated in future climate agreements.

The most effective international environmental agreements have relied on trade restrictions. But these agreements have been so effective that trade has not actually needed to be restricted. A new climate regime needs to be designed with this experience in mind.

The current regime was developed without much thought being given to the use of trade restrictions. The most plausible way forward is a more fragmented approach, with different agreements addressing different gases and sectors, often supported by trade restrictions. Trade restrictions should only be used where they can be effective-and, as noted before, they will be effective mainly in situations where the credible threat of using them suffices to promote cooperation. 


\section{REFERENCES}

Aldy, J.E. and R.N. Stavins eds. (2007), Architectures for Agreement: Addressing Global Climate Change in the Post-Kyoto World (Cambridge: Cambridge University Press).

Aldy, J.E. and R.N. Stavins eds. (2010), Post-Kyoto International Climate Policy: Implementing Architectures for Agreement (Cambridge: Cambridge University Press).

Babiker, M.H. (2005). 'Climate Change Policy, Market Structure, and Carbon Leakage,' Journal of International Economics, 65, 2, 421-445.

Barrett, S. (2010) 'Climate Change and International Trade: Lessons on their Linkage from International Environmental Agreements,' prepared for Conference on Climate Change, Trade and Competitiveness: Issues for the WTO, World Trade Organization, Geneva, 16-18 June 2010.

Barrett, S. (2007), Why Cooperate?: The Incentive to Supply Global Public Goods (Oxford: Oxford University Press).

Barrett, S. (2006), “Climate Treaties and 'Breakthrough' Technologies,” American Economic Review (Papers and Proceedings), 96, 2, 22-25.

Barrett, S. (2003), Environment and Statecraft: The Strategy of Environmental Treaty-Making (Oxford: Oxford University Press).

Blanco, E. de la R. and E. Greitzer (2010). ‘Subsonic Civil Transport Aircraft for a 2035 Time Frame, in ICAO Environmental Report 2010; at http://www.icao.int/env/Pubs/EnvReport10.htm, pp. 91-94. 
Cowan, R. (1990). 'Nuclear Power Reactors: A Study in Technological Lock-in,' Journal of Economic History 50, 3, 541-567.

Davis, S.J. and K. Caldeira (2010), 'Consumption-Based Accounting of CO2 Emissions,' Proceedings of the National Academy of Sciences www.pnas.org/cgi/doi/10.1073/pnas.0906974107.

Ellerman, D. and B.K. Buchner (2007) 'European Union Emissions Trading Scheme: Origins, Allocation, and Early Results,' Review of Environmental Economics and Policy 1, 1, 66-87.

Elliott, J., I. Foster, S. Kortum, T. Munson, F. Pérez Cervantes, and D. Weisbach (2010), 'Trade and Carbon Taxes,' American Economic Review: Papers \& Proceedings 100, 465469.

Fullerton, D. and D. Karney (2010), 'Negative Leakage,' mimeo, University of Illinois at Urbana-Champaign.

ICAO (2010), ICAO Environmental Report 2010, at http://www.icao.int/env/Pubs/EnvReport10.htm.

Kallbekken, S. and J. Hovi (2007), 'The Price of Non-Compliance with the Kyoto Protocol: The Remarkable Case of Norway,' International Environmental Agreements, 7, 1-15.

McCollum, D., G. Gould, and D. Greene (2009), Greenhouse Gas Emissions from Aviation and Marine Transportation: Mitigation Potential and Policies, Prepared for the Pew Center on Global Climate available at http://www.pewclimate.org/technology/report/aviation-and-marine.

Rumizen, M., N. Brown, R. Altman, and L.O. Maurice (2010), 'A Global Fuel Qualification and Certification Protocol, in ICAO Environmental Report 2010; at http://www.icao.int/env/Pubs/EnvReport10.htm, pp. 178-181. 
Stiglitz, J.E. (2006), 'A New Agenda for Global Warming,' Economists' Voice; at http://www.bepress.com/cgi/viewcontent.cgi?article=1210\&context=ev.

Stokstad, E. (2010), 'Trade Trumps Science for Marine Species at International Meeting,' Science 328, 26-27.

Velders, G.J.M., S.O. Anderson, J.S. Daniel, D.W. Fahey, and M. McFarland (2007), 'The Importance of the Montreal Protocol in Protecting Climate,' Proceedings of the National Academy of Sciences, 104, 12, 4814-4819.

Wara, M. (2006), 'Measuring the Clean Development Mechanism's Performance and Potential,' Working Paper No. 56, Program on Energy and Sustainable Development, Stanford University; at http://iis-db.stanford.edu/pubs/21211/Wara CDM.pdf.

Wara, M. (2007), 'Is the Global Carbon Market Working?' Nature 445, 595-596.

Webster, D.G. (2011), 'The Irony and the Exclusivity of Atlantic Bluefin Tuna Management,' Marine Policy 35, 249-251.

Whalley, J. (2011), 'What Role for Trade in a Post 2012 Global Climate Policy Regime,' paper prepared for the international conference, Climate Change Policies and the World Trading System: the Challenges Ahead, Paris, June 2011. 